\title{
Review of Ukrainian health care reformation on principles of family medicine
}

\author{
VICTORIA I. TKACHENKOA, B, D-F
}

Department of Family Medicine, Shupyk National Medical Academy of Postgraduate Education, Kiev, Ukraine

A - Study Design, B - Data Collection, C - Statistical Analysis, D - Data Interpretation, E - Manuscript Preparation, F - Literature Search, G - Funds Collection

Summary This article presents the steps of family medicine implementation in Ukraine, the results and problems of reorganization of the health system, educational and economic problems and the role of the Institute of Family Medicine at the Shupyk National Medical Academy of Postgraduate Education in all processes. The new structure of primary care includes centers with administrative facilities, several ambulatory primary care clinics and emergency care departments. The main problem is to provide a substantial quantity of general practitioners (GPs) to cover affordable primary care for the Ukrainian population (42 million). The target is approximately 28,000 working GPs for the short period of 2011-2020, where in 2016, there were approximately 14,000 GPs. Other problems include the insufficient financing and equipment of primary care centers, low number of computers, paper medical records and low salary. The situation has been worsened since 2014 when the antiterroristic operation was started and funding of primary care was cut. Further steps of reformation according to the plan of the Ministry of Health of Ukraine are: reformation of the financing system, organization of hospital areas, autonomization of health establishments, creation of centers of public health, wide implementation of licensing and health insurance, state reimbursement of medications for patients, implementation of syndrome classification ICPC-2, improvement of national clinical guidelines and implementation of digital medical records. The reformation of the health system of Ukraine upon the principles of family medicine for 30 years, more active in the last 5 years, showed some positive results, but at the same time determined the existence of quality problems in medical education and financing of primary care.

Key words: health care reform, results, reorganization, primary health care, family medicine, Ukraine.

Tkachenko VI. Review of Ukrainian health care reformation on principles of family medicine. Fam Med Prim Care Rev 2017; 19(4): 425-429, doi: https://doi.org/10.5114/fmpcr.2017.70820.

\section{Background}

Ukraine is the second largest country in Europe, situated in the south-east between the neighboring countries of the Russian Federation, Belarus, the Republic of Moldova, Romania, Hungary, Slovakia and Poland. Ukraine has a territory of $603,549 \mathrm{~km}^{2}$ and a population of 42.4 million (2017). The country achieved independence in August 1991 after the USSR dissolved. This was the start of a difficult transition period towards a democratic society and a market economy. As former country of the USSR, Ukraine inherited an extensive and highly centralized Semashko system, which was not possible to maintain through the economic downturn that followed independence in 1991. There has been considerable decentralization in the system, i.e. deconcentration of functional and managerial powers at the regional and sub-regional level. Regional and local health directorates are responsible for health facilities in their territory and are functionally subordinate to the Ministry of Health of Ukraine (MHU), but managerially and financially answerable to the regional and local self-government [1, 2].

\section{Ukrainian health system}

The structure of the Ukrainian health system (Figure 1) consisted of different levels: inpatient care, outpatient care and public health services (this state service is hierarchically organized parallel to the other health care services and has branches throughout the country). Inpatient care was provided by a network of hospitals (secondary, tertiary and specialized levels): district, region, city and specialized hospitals. Outpa- tient services were provided by policlinic departments of hospitals, departments of territorial policlinics, rural ambulatories and feldsher-midwife points (FAPs) in villages, where only highly qualified nurses (feldsher) are employed. The primary and secondary levels of care were not strictly separated, with specialists providing care both to the patients referred to them by district doctors (internist or pediatrician) and to those who come to visit them directly. Public health was responsible for the state sanitary-epidemiological service (SES). The focus of SES is infection control and environmental protection (ensuring the quality and safety of water, air, soil and food) [1, 2].

The health care system (HCS) in Ukraine was financed through central and decentralized government budgets and coordinated and managed at the central level by MHU and at the local level by region health authorities. Health care expenditure in Ukraine is low by regional standards in contrast to European countries and has not increased significantly as a proportion of GDP (2000 - 4.6\%: $2014-8.8 \%$ ) [1-4]. Officially, Ukraine has a comprehensive guaranteed package of health care services provided free of charge at the point of use as a constitutional right; nevertheless, user charges are widely levied in the Ukrainian HCS. Most health financing comes from general government revenues raised through taxation (value added taxes, business income taxes, international trade and excise taxes). Personal income tax is not a significant contribution to total revenues. The role of voluntary health insurance is insignificant, as few people can afford the premiums. Out-of-pocket payments account for a significant proportion of total health expenditure, and there are some limited voluntary health insurance (VHI) schemes. VHI still plays a very minor role in health care financing in Ukraine. Despite the relative growth in the number of insured people 
and insurance premiums, only $2.5 \%$ of the population use $\mathrm{VHI}$, and its contribution to total health care expenditure is $0.8 \%$. The $\mathrm{VHI}$ is offered exclusively by private insurance companies that are often not specialized in health $[1,2]$. The reorganization of health system has been providing since 2011 with creation of primary care centres with decentralization of financing according to European experience.

\section{Overview of the health system}

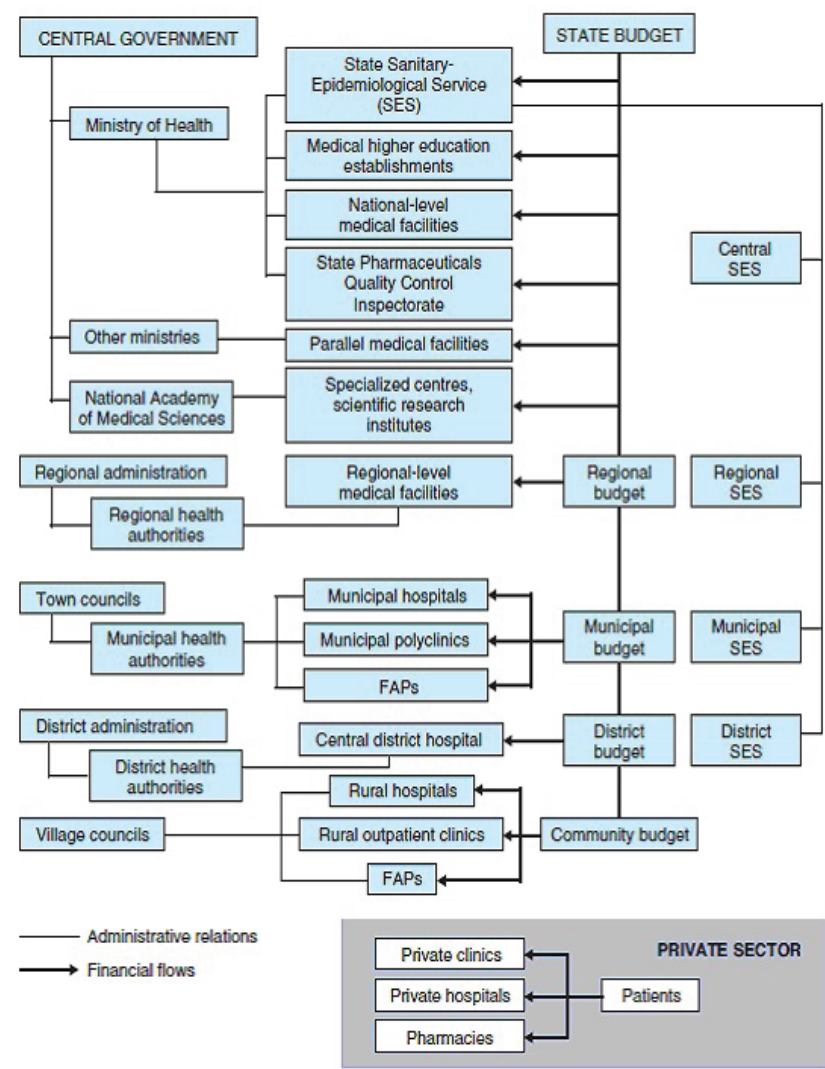

Figure 1. The structure of Ukrainian health system from 1980-2010

\section{Family medicine in Ukraine}

It is widely considered that the implementation of family medicine in Ukraine began in its modern sense in 1987, when the Lviv regional experimental program was implemented and the model of HCS transformation from district internists (physicians) and pediatricians to family oriented principles was started. It was the first project of family medicine implementation in the USSR. A great contribution to the implementation of family medicine in the Lviv region of Ukraine was made by a team of enthusiasts led by Prof. E. Zaremba. At that time, after receiving international experience, 3-year postgraduate specialist (vocational) training in General Practice/Family Medicine (GP/FM) was started locally at the therapeutic department at Lviv National Medical University, named after Danylo Galician (1992), and the first general practitioners (GPs) graduated, the first primary care clinics were organized and the Lviv Regional Association of Family Physicians was created (1995). The positive results of the Lviv pilot program led to the development of the Basic Laws of Ukrainian Health care system (1992), which was approved by the Ukrainian Parliament and identified the priority of the development of primary care on the basis of family medicine in the country [5-7].

Since then, Ukraine has begun to build a regulatory framework for the widespread implementation of a new model of primary care based on the principles of family medicine, and the pilot projects continued in Komsomolsk (Poltava region), Voznesensk, Zaporizhzhia, Khmelnytsky, Kharkiv and other ar- eas. However, in other regions, the system remained largely unreformed until $2011[1,2,7,8]$.

The need of a new kind of specialist training - GP internship, foundation of educational departments of family medicine, development of a new medical specialty "GP/FM" and professional association - has appeared. The educational departments of GP/FM have begun to be set up in medical universities in Ukraine.

In Kiev, the first educational family medicine department was established in 1996 at the Shupyk National Medical Academy of Postgraduate Education and was headed by Prof. G. Lysenko. The department become the leading between others and develops educational programs for postgraduate education of GPs. The compatible efforts of Prof. G. Lysenko and Prof. E. Zaremba led to the foundation of the Ukrainian Association of Family Medicine in 1997, which became a member of the World Organization of National Colleges, Academies and Academic Associations of General Practitioners/Family Physicians (WONCA) in 1999 and joined the European region territorially. Prof. G. Lysenko was elected as the first president of the Ukrainian Association of Family Medicine, and since that time, the major historical events of family medicine development have taken place through his assistance. Thanks to the efforts of Prof. G. Lysenko (2 July 1947-9 Oct 2013), who is considered to be the founder of family medicine in Ukraine, the first professional scientific journal "Family Medicine" was created in Ukraine in 1999 , the first medical faculty named "Faculty of GP/FM", which united ten departments, was created in 2005, the faculty was reorganized into the Institute of Family Medicine of the Shupyk National Medical Academy of Postgraduate Education (IFM NMAPE) in 2009, the academic and scientific specialty "GP/FM" was approved in 2010, and the first specialized academic council for defense of scientific thesis and PhD dissertations in the field of GP/FM was created [7-13]. The first dissertation in GP/FM was defended in 2012 (V. Mintser) under his supervision.

Since 1992, the education of GPs had consisted of two stages: undergraduate and postgraduate training. The highest medical education is provided by eighteen state university-level medical schools and faculties, including three postgraduate medical academies. Undergraduate medical education usually lasts for six years and provides the courses of general practice/ /family medicine as a part of a course of outpatient care over a few weeks during the last year of undergraduate curricula [1, $2,5-7]$.

Since 1996, postgraduate specialist training in the specialty "GP/FM" has been conducted in several ways in Ukraine: 2 years of internship, during which the curriculum provides $50 \%$ of fulltime and $50 \%$ of distance learning at the work place; 6 -month courses of re-specialization (retraining). Postgraduate specialist training is provided by the postgraduate educational departments of GP/FM $[7,12,13]$.

The training is based on educational standards which are developed by a work group of representatives of educational departments according to international guidelines and which are approved by MHU and the Ministry of Education. MHU supervises the content, level and number of state educational standards, qualification requirements for specialist training and monitors the quality of training at undergraduate and postgraduate levels. Educational standards are mandatory for all medical educational establishments. However, the model of curricula and syllabuses can be changed for not more than $15 \%$ of the total number of hours by medical universities [1, 2, 7, 12-14].

According to the Bologna Process, MHU has implemented state integrated licensing examinations, which consists of two state licensing examinations during undergraduate training, after studying basic disciplines ("Step 1") and after completing the full training course ("Step 2"). In 2004, the state licensing examinations for specialist training (internship) were introduced, which is equivalent to "Step 3" in the current system of higher medical education $[1,2]$. 
ORGANIZATION OF PRIMARY CARE IN UKRAINE

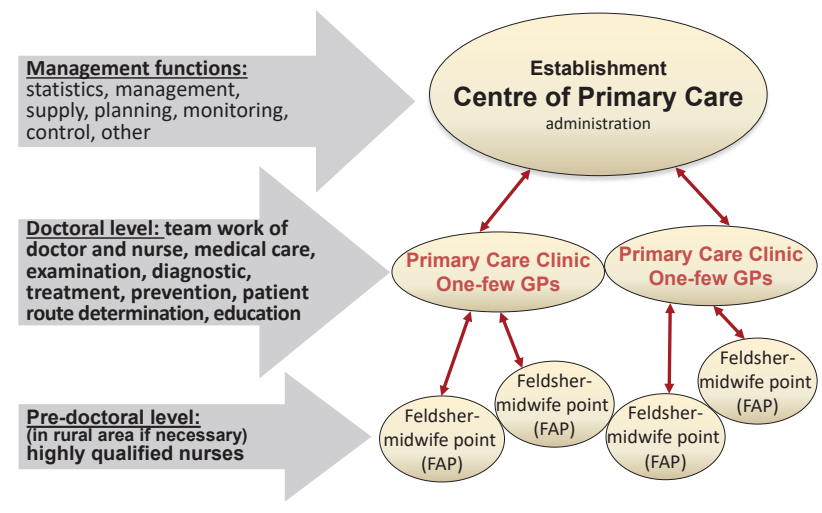

Figure 2. The dynamic of number of positions of GPs and working GPs in Ukraine in 2000-2016

Thanks to these implementation and reorganization of the educational system, Ukraine received a significant increase of the number of GPs, amounting 8.1 thousand in 2010 (Figure 2 ), along with nurses in general practice who were educated at medical nurse colleges. But this was not enough to cover the entire Ukrainian population by primary care. In 2010, GPs made up a third (32.9\%) of all primary care specialists, and the percentage of GPs in contrast to specialists amounted to $4.8 \%$ in Ukraine $(7.7 \%$ in 2013$)[1,2,7,8]$.

From 2000 till 2010, the organization of primary care delivery continued to be based on the territorial-district principle, by which the area served by a particular primary care unit is divided into areas with a certain number of residents. Ukrainians have been granted free choice of their primary care doctor; however, this has not yet been widely implemented. The patient's option to change the primary care provider is restricted by the lack of GPs and by the territorial boundaries in rural area. Primary care has been provided within an integrated system by district primary care specialists - GPs, district internists (physicians), district pediatricians employed by state polyclinics or appropriate polyclinic departments, and by highly qualified nurses - feldshers in FAPs in villages. Primary care doctors provided general medical care to populations living in matched area (district) in outpatient settings or during home visits, and they were responsible for preventive work, monitoring of patients with chronic diseases, provision of health education and immunization, promotion of healthy lifestyles and providing referrals to specialists and hospitals. Primary care nurses performed mostly auxiliary functions: under a doctor's supervision, they helped with medical documents, performed certain examinations during the visit (taking of temperature, blood pressure, etc.) and provided health education to the patients, but the feldsher could make a diagnosis and prescribe some medications, as they had worked without a doctor in FAP. The district internist and district pediatrician provide the care only like internists (specialist in internal diseases). In contrast to them GPs can provide primary care as to children as to adults, also can perform basic surgical treatment of wounds, the immobilization of fractures and the dynamic monitoring of pregnant women with a normal course of pregnancy during the antenatal and postnatal periods. However, especially in urban areas, people are reluctant to bring very young children to GPs who were retrained by adult district internists. The retraining program of six months is viewed as inadequate, while in rural areas, district internists had been, de facto, working as GPs prior to retraining. Consequently, in some areas, GPs only work with children older than 3 or 7 years of age, and the overwhelming majority of actual GP facilities are located in rural areas (70\%). That health care was for from WONCA standard that is why the new wave of health system reorganization was started in 2011 [1, 2, 5-8].
In 2011, the amendment to the Basic Laws of Ukrainian HCS concerning the improvement of primary care and the Law about its reorganization in four pilot regions - Vinnytsia, Dnipropetrovsk, Donetsk and Kyiv were approved, that determined the creation of primary care centers made according to European experience. The structure of primary care centers includes an administrative center, several outpatient primary care clinics, emergency care departments and FAPs (Figure 2). According to the law, the primary care centers can employee general practitioners and district doctors until 2020. The aim for 2011-2020 was to retrain district pediatricians and district internists as general practitioners and to educate young GPs to make it possible to cover the entire population by GP care as only employees of primary care centers. The dynamic of number of positions and working GPs is depicted on Figure 3. It is considered that primary care will be provided by a team of one GP and two nurses of general practice/family medicine for a population in an urban area of 1,500 citizens and a rural area up to 1,200 citizens of any age. In 2012, next year after the start of reorganization of primary care in pilot regions but without deep analyzing of its results, the government decided to create the primary care centers in whole country, but appropriate funding and preparation for this was not envisaged (given) [14, 15].

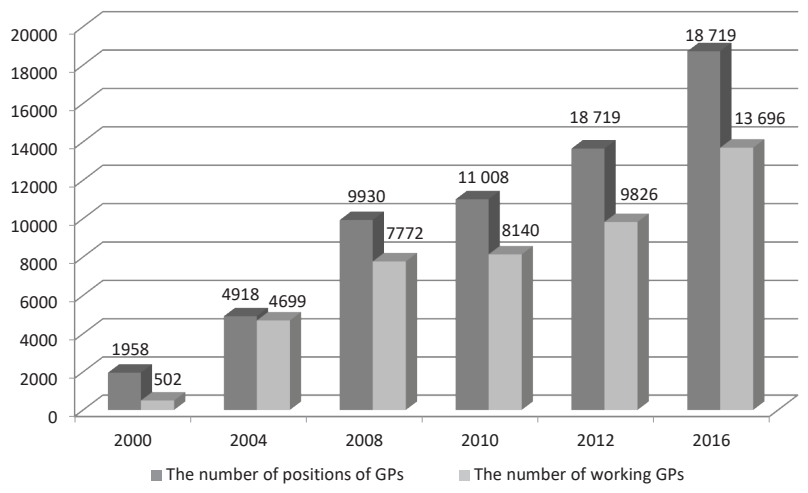

Figure 3. The dynamic of number of positions and working GPs during the organization of primary care in Ukraine

In this situation, by order № 466 of the MHU from 7 Jun 2010 IFM NMAPE was entrusted with the following functions: organization and implementation of a qualitative and effective system of specialist training and retraining in "GP/FM"; coordination of research in family medicine; scientific and methodological support of implementation of family medicine in primary care and formation of the strategic direction of its development [9-14].

The main problem of GP training in the stage of HCS reformation was the need to provide an adequate quantity of GPs to cover affordable primary care for the Ukrainian population. The target is approximately 28 thousand working GPs for the fairly short period 2011-2020, when, for 25 years of family medicine implementation, the number of GPs was approximately 10,000 in 2012 (Figure 3). This is the reason why the MHU decided to continue retraining of district internists and pediatricians during short 6-month courses of re-specialization. The economic crisis and low funding of HCS and education restricts the possibility of prolongation of GP specialist training to the internationally recommended period of 3 years. However, the quality of education and practical skills are insufficient in this situation $[3,4$, 14-17]. In order to improve the quality of GP training, the IFM NMAPE provides advanced training and thematical courses of postgraduate studies continuing professional education in various aspects of family medicine with the use of new educational and modern computer technologies and distance learning. Different educational techniques are used during the education process, such as lectures, workshops, work in small groups, brain storming, case-oriented or problem-oriented education. The departments constantly update the curriculum according to 
international standards and the recommendations of WONCA to improve the quality of education. The IFM NMAPE also conducts special training for those training in the working place stage. The exclusive project of distance continuing education in medical scientific journals is conducted every month - the series of lectures and clinical cases are printed with the follow-up questions (survey), if a doctor sends the correct answers he received the certificate. Scientific workshops on topical issues of family medicine and teleconferences are held to improve the results of HCS reformation. IFM NMAPE keeps publishing and updating manuals and textbooks for GPs and those training in family medicine. Practical skills can be improved in IFM NMAPE by family doctors in 61 clinics, including 33 inpatient clinics, 10 outpatient clinics, 3 specialized family medicine centers, 12 centers of general practice or in training centers equipped with the instruments, tools and mannequins $[7,12,13]$.

Nevertheless, the president of WONCA, Prof. Amanda Howe, published in "WONCA NEWS" a report about a visit to the Ukrainian Association of Family Medicine in October 2013. She wrote: "I would like to report the following good news: reforms in the health system of Ukraine, which supports the development and prioritization of primary health cares are now under way in four pilot regions, and there was a clear commitment to the establishment of family medicine and modernization of primary care across the whole country over the next phase leading up to 2020. However, challenges remain, and the Ukrainian Association of Family Medicine Council had a list of recommendations which remain to be actioned, which include issues around training capacity, support for Family Medicine $C P D$, Family Medicine exposure in basic medical school training and a number of other issues. The numbers of Family Medicine practitioners are expected to more than double, so while these are exciting developments, the challenge for the existing Family Medicine faculty is great. It will be really important to support Ukrainian family medicine in what is a crucial era. Prof Lysenko left a huge legacy of good work and goodwill, but, as in so many countries, the expectations of family medicine are huge, and lack of resources or effective stabilization of the new primary care reforms could undermine what otherwise would be a strong and effective model of care that is sorely needed by the Ukrainian population" [18]. The positive features of primary health care were mentioned by other authors $[3,4,16$, $17,19-20]$.

Nowadays, according to data of $\mathrm{MHU}$, the reorganization of HCS with the creation of 616 primary care centers has been done in all regions of Ukraine. There are about 20,474 doctors of primary care (2016), including district internist, district pediatricians and approximately 14 thousand GPs, employed in primary care centers. Theoretically, this is $0.5 \mathrm{GPs}$ per 1,000 people, and this isn't enough to cover primary care. In practice, nationwide, $13 \%$ of doctors working in primary care serve fewer than 1,000 people (adults and children), and about one-fifth (20.4\%) provide care for more than 2,500 assigned patients. In rural areas, the number of doctors serving more than 2,500 patients comes close to a third (29.1\%). The number of medical human resources per capita has increased gradually, but the absolute number of doctors and nurses in rural areas and in primary care has a high turnover due to the low wages and low status of this specialty, as well as the limited possibilities for professional development. Although FAPs provide primary care services as well, the shortage of medical personnel in rural areas causes a number of problems with the accessibility and quality of medical care due to a low population density of 30-70 people per $1 \mathrm{~km}^{2}$ or the long distance. About a third of rural communities have no medical facilities within their territory $[3,4,21]$.

The total number of outpatient contacts per citizen per year is rather high in Ukraine and is significantly higher than in the countries of Central and Eastern Europe and in EU countries. The high rate of visits per capita is a result of the Ukrainian method of paying for services based on capacity measures. Ac- cess to secondary care is still not regulated. Patients may seek care from a specialist directly without a formal referral from their primary care doctor, and this option is widely used [3, 4].

At the same time, the medical workforce is ageing rapidly, as new graduates choose to work outside the state health system or seek opportunities abroad. Nowadays, the salary of a young GP in Ukraine is minimal - 3,200 hryvnas (110 Euro), and after deduction of taxes, it becomes even less - 90 Euros. The salary of a GP with experience can reach a maximum of $200 \mathrm{Eu}$ ros per month, and this is the reason why doctors go abroad or change the profession. Ukraine has been remunerating public sector health care professionals using fixed salary scales. Professional salaries for the majority of medical personnel are set in accordance with their qualification, which reflects a worker's professional level (no category, first category, second category and highest category). Managers at government-financed health care facilities have the right to raise salaries within the salary fund provided by line-item budgets. A special program of financial motivation for primary care workers was developed and implemented by the Cabinet of Ministers during 2012-2013, but was canceled because of lack of budget due to antiterrorist operations [15, 21].

In January 2017, according to data of the State Committee of Statistics, the monthly salary without deduction of taxes is: minimal $-3,200$ hryvnas (110 Euro), average $-6,000$ hryvnas (206 Euro), and the average salary of health system workers is 4,450 hryvnas (153 Euro). The ratio of household costs to average salary is $53.7 \%$. The highest salary is 27,340 hryvnas ( 940 Euro) for air-transport workers, while newspapers say that the salary of politicians is upper 3,000 Euros [21].

The number of privately practicing GPs is relatively small ( $0.8 \%$ of the total number of doctors in this specialization). The majority of privately practicing GPs work under contracts, either with the local authorities or with insurance companies [1-4].

The other big problems of reorganization of the HCS are the lack of financing and insufficient equipment of primary care centers, low number of computers for the work of GPs and paper medical records, which decreased the status of GPs $[3,4,7]$.

For improvement of the quality and status of general practice, the Departments of Family Medicine began to motivate GPs to conduct research in various issues of family medicine, including the study of risk factors and the development of prevention programs for the most common diseases in general practice. To date, more than $15 \mathrm{PhD}$ theses in "GP/FM" and 2 theses for the highest scientific degree in Ukraine - Doctor of Medical Sciences in GP/FM (V. Tkachenko, L. Matuha) - have been defended since the new scientific and research specialty and PhD course were established. The cooperation of IFM NMAPE with the Royal Scottish College of Family Medicine (2008-2010) and the Institute of NIVEL (Netherlands, 2008-2010) assisted in receipt of international support and experience. The Ukrainian representatives of the WONCA Council, Europe Council of Vasco da Gama Movement, EURACT, EQuip, EGPRN, Council of Ukrainian Association of Family Medicine and the Ukrainian youth movement of family doctors being employees of the Institute (O. Shekera, V. Tkachenko, L. Khimion, L. Matuha, I. Sadovnik) take part in international conferences, meetings and courses. The staff of the IFM NMAPE was also involved in improving the legislative documents of Ukraine towards family medicine and training regulations, national guidelines and protocols. There are approximately 123 national protocols in the management of common diseases and syndromes in primary care that were developed and approved by MHU [7, 9-13].

After the announcement in 2010 of the $19^{\text {th }}$ of May as World Day of Family Doctor by World WONCA, the proposal to establish the professional holiday "Day of Family Medicine" in Ukraine was sent to the government for celebration each year on the $19^{\text {th }}$ of May. The celebration of this day in Ukraine was initiated and started by the institute in 2015. Nowadays, the 
project of law about primary care based on family medicine was developed with participation of employees of IFM NMAPO (O. Shekera, V. Tkachenko) and is on stage of voting in parliament.

\section{Future of HSC in Ukraine}

The further steps of reformation according to the plans of MHU plans are: reformation of the financing system of HCS, organization of hospital areas, autonomization of health establishments, creation of centers of public health (reorganization of SES), wide implementation of licensing and health insurance, state reimbursement of medications for patients, implementation of syndrome classification ICPC-2, improvement of national clinical guidelines and implementation of digital medical records [14, 15].

The reformation of the HCS of Ukraine upon the principles of family medicine for 30 years, which has been more active in the last 5 years, showed some positive results, but at the same time determined the existence of quality problems in medical education and the financing of primary care. The activity of IFM NMAPE takes an active role in quality improvement of general practice and primary care in Ukraine. The expansion of international contacts and collaboration with foreign partners strengthens the implementation of best practices and experience.

Source of funding: This work was funded by the author's own resources.

Conflict of interest: The author declares no conflict of interests.

\section{References}

1. Lekhan V, Rudiy V, Richardson E. Ukraine: health system review. World Health Organization on behalf of the European Observatory on Health Systems and Policies. Health System in Transition 2010; 12(8): 1-183. Available from URL: http://www.euro.who.int/_data/ assets/pdf_file/0010/140599/e94973.pdf.

2. Primary care in the WHO European Region. Evaluation of structure and provision of primary care in Ukraine. A survey-based project in the regions of Kiev and Vinnitsa. Geneva: World Health Organization; 2010.

3. Lekhan VM, Slabkyy HO, Ginsburg VH, et al. Development of primary health care in Ukraine in the light of global trends. The Pharma Innovation Journal 2014; 3(5): 40-45.

4. Lekhan V, Kaluski DN, Jakubowski E, et al. Reforming the Ukrainian health system at a time of crisis. Eurohealth Incorporating Euro Observer 2015; 21(2): 14-17.

5. Sklyarova YC. The life: scientific, educational and therapeutic activities of academician of Ukraine, MD, distinguished Professor of Lviv National University the medical Galician Daniel Zaremba Eugenia Homivny. Lviv: Pyramid; 2015.

6. Chopey IV. Family medicine in Ukraine: problems and prospects of introduction. Kiev: Nora-Press; 2004.

7. Tkachenko VI. History and current status of primary health care in the world and in Ukraine, the legal framework of implementation of family medicine in Ukraine. Fam Med 2015; 3: 12-18.

8. Slabkiy GA. Situational analysis of family medicine in Ukraine, 2010. Kyiv: Ukrainian Institute for Strategic Studies Ministry of Health of Ukraine; 2011: 28.

9. Voronenko $Y$, Lysenko G. The introduction of family medicine as a scientific specialty - a necessary condition for the development of family medicine in Ukraine. Ukr Med Chasopys 2007; 6(62): 27-32.

10. Tkachenko V. The evolution of primary care research in Ukraine. CMAJ [serial online] 2014 Nov [cited 19.11.2014]. Available from URL: http://cmajblogs.com/the-evolution-of-primary-care-research-in-ukraine/.

11. Lysenko G, Tkachenko V. The role of postgraduate education and scientific researches in reformation of primary care on principles of family medicine in Ukraine. Proceedings of the $18^{\text {th }}$ Wonca Europe Conference 2012 "The art and science of general practice"; 2012 July 4-7; Vienna, Austria; 2012: 105.

12. Voronenko YV, Shekera OG, Tkachenko VI, et al. Approaches to specialist training of general practitioners in the Ukraine and European countries. Ukr Med Chasopys 2014; 3(101): 116-120. Available from URL: umj.com.uaswp/wp-content/uploads/2014/06/4280.pdf.

13. Lysenko G, Tkachenko V. The features of postgraduate education and creation of medico-technological documents in conditions of intensive primary care' reformation in Ukraine. Proceedings of the $20^{\text {th }}$ World Wonca Conference "Family Medicine - Care for Generations"; 2013 June 25-29; Prague, Czech Republic; 2013: 862.

14. Legislative documents of Health Ministry of Ukraine (website). Available from URL: http://www.moz.gov.ua.

15. Main page of "Laws of Ukraine" (website). Available from URL: http://zakon2.rada.gov.ua/laws.

16. Ruskykh K. Primary healthcare reform in Central and Eastern Europe. Lessons for Ukraine Case-ukraine.com.ua [serial online] 2013 Jan [cited 09.01.2013]. Available from URL: http://www.case-ukraine.com.ua/en/reformi-pervinno\%d1\%97-medichno\%d1\%97-dopomogi-v-kra\%d1\%97nax-centralno\%d1\%97-ta-sxidno\%d1\%97-yevropi-uroki-dlya-ukra\%d1\%97ni-2/.

17. Ruskykh K. Primary healthcare reform: a lot of noise, little real changes. Case-ukraine.com.ua [serial online] 2014 Feb [cited 12.02.2014]. Available from URL: http://www.case-ukraine.com.ua/en/reforma-pervinno\%d1\%97-medichno\%d1\%97-dopomogi-bagato-shumu-malo-yakisnix-zmin-2/.

18. Ukrainian loss and legacy - Amanda Howe reports. A visit to the Ukrainian Association of Family Medicine (UAFM). WONCA News 2013; 11(39): 7-8. Available from URL: http://www.globalfamilydoctor.com/News/UkrainianLossandlegacyAmandaHowereports.aspx

19. Primary Health Care now more than ever: the world health report. Geneva: WHO, 2008, 125.

20. Kühlbrandt Ch, Boerma W. Primary care reforms in countries of the former Soviet Union: success and challenges. Eurohealth Incorporating Euro Observer 2015; 21(2): 3-7.

21. State Statistic Service of Ukraine. Demographic and social statistics in Health 1990-2016 (renewed 06/30/2017). Available from website: http://www.ukrstat.gov.ua/.

Tables: 0

Figures: 3

References: 21

Received: 31.03.2017

Revised: 12.05 .2017

Accepted: 12.05 .2017
Address for correspondence:

Victoria Tkachenko, MD, PhD, Assoc. Prof.

Department of Family Medicine

Shupyk National Medical Academy of Postgraduate Education Dorogozhytska 9

Kyiv, 04112

Ukraine

Tel.: 0677574596

E-mail:witk@ukr.net 